\title{
A path dependence na inserção internacional da Guiana
}

\author{
Path dependence and Guyana's \\ international insertion
}

DOI: $10.21530 /$ ci.v12n1.2017.613

Marcelino Teixeira Lisboa ${ }^{1}$

Ronaldo Silva ${ }^{2}$

\section{Resumo}

Este texto trata da inserção internacional da Guiana através da adesão a processos de integração e organizações internacionais no período de 1966 a 2015. O objetivo é demonstrar como a inserção guianense nesse aspecto criou, ao longo do tempo, uma dependência da trajetória adotada logo após a independência. A análise é realizada com base nos preceitos da path dependence, entendida como uma dependência gerada pela trajetória traçada em determinado caminho, escolhido em um dado momento histórico, dependência essa que se consolida a cada passo trilhado na mesma trajetória. Concluiu-se que, no período analisado, a Guiana teve um eixo de sua integração voltado para a Europa e outro para o Caribe, a partir dos anos de 1970, que seguiram sendo reforçados ao longo do tempo; a partir dos anos 2000, o país passou também a aderir a processos voltados para a América Latina, mas sem deixar as relações anteriores, ramificando sua inserção internacional, que foi institucionalizada desde a sua independência.

Palavras-chave: Guiana; Inserção internacional; Path dependence; Política externa.

\begin{abstract}
This text addresses the international insertion of Guyana through the adherence to integration processes and international organizations in the period from 1966 to 2015 . The objective is to demonstrate how the Guyanese relations have become dependent on the trajectory adopted shortly after independence. The analysis is based on the precepts of path dependence,

1 Professor do Curso de Relações Internacionais e Integração da Universidade Federal da Integração Latino Americana (UNILA). E-mail: marcelino.lisboa@yahoo.com.br

2 Mestrando do Programa de Pós-Graduação em Integração Contemporânea da América Latina (PPG-ICAL). E-mail: ronaldosilvars@hotmail.com

Artigo submetido em 14/01/2017 e aprovado em 16/03/2017.
\end{abstract}


understood as dependence generated by the trajectory traced in a particular path, chosen at a given historical moment and consolidated with each step taken in the same trajectory. It was concluded that in the period analyzed Guyana had one axis of its integration turned to Europe and another to the Caribbean, from the 1970s, which was reinforced over time; from the 2000s on, the country began to adhere to processes aimed at Latin America, but without abandoning previous relations, branching out the international insertion that was institutionalized since its independence.

Keywords: Guyana; International relations; Path dependence; Foreign policy.

\section{Introdução}

A República Cooperativa da Guiana ${ }^{3}$ é um país independente desde 1966, até quando era uma colônia inglesa. Em 2016, o país completou 50 anos de independência, com liberdade de definir suas diretrizes políticas e seu modelo de inserção internacional. Durante esse meio século, diversas mudanças ocorreram no cenário internacional, tal como o fim da Guerra Fria, períodos de governos militares, redemocratização e crises econômicas. Além desses, outros dois acontecimentos relevantes foram a criação de diversas organizações internacionais e o avanço de processos de integração entre os Estados. Dentro dessa temática, este texto discorre acerca dos processos de integração e das organizações internacionais a que a Guiana aderiu ao longo de sua curta história como país independente, buscando a resposta à seguinte questão: qual foi a trajetória traçada pela Guiana em sua inserção internacional, no que diz respeito à sua adesão a processos de integração e participação em organizações internacionais?

A partir dessa indagação, o objetivo do artigo é demonstrar como a inserção internacional da Guiana, relativamente aos processos de integração e da participação em organizações internacionais, passou por alguns momentos decisórios cujas alternativas adotadas foram influenciadas por condições historicamente construídas; além disso, tais alternativas foram reforçadas ao longo do tempo. Para tanto, aborda-se a inserção internacional da Guiana a partir da visão da path dependence,

3 O nome tão singular do país foi instituído em 23 de fevereiro de 1970, quando deixou de fazer parte da monarquia britânica e passou a utilizar o termo "Co-operative" no nome oficial. Nessa ocasião, foi instituído um terceiro setor na economia, o cooperativo, que deveria ter primazia em relação ao setor estatal e ao privado. De acordo com a Constituição de 1970, o cooperativismo passaria a ser o princípio dinâmico da transformação socialista, passando a permear toda as inter-relações sociais (GUYANA, 1970). Um exemplo da importância do setor cooperativo são as instituições econômicas estatais criadas, como Guyana National Cooperative Bank, Guyana Agricultural Co-operative Development Bank, Guyana National Cooperative Bank Trust Company (LIMA, 2011). 
cujas ferramentas permitem um ponto de vista que considera os fatores históricos, as decisões tomadas e a abordagem das relações - causais ou não - entre os eventos ao longo do tempo.

O recorte temático define o primeiro contributo do artigo, que é o de colaborar para um melhor entendimento das relações internacionais da Guiana, visto que ainda é um Estado pouco explorado pela literatura das relações internacionais no Brasil. A justificativa para se analisar a adesão da Guiana aos processos de integração e às instituições internacionais, deve-se ao fato de que são itens da pauta da política externa do país presentes em todo o período analisado e nos quais observam-se mudanças passíveis de serem examinadas a partir da proposta metodológica. A segunda contribuição é de cunho teórico, realizando uma abordagem a partir de ferramentas conceituais e metodológicas ainda pouco comuns no campo das relações internacionais, com a análise a partir da path dependence. Apesar de possuir elementos úteis para as relações internacionais, tal perspectiva ainda é relativamente nova no campo científico, se for considerado que sua sistematização como teoria ocorreu na década de 1990 na economia e nos anos 2000 na ciência política, sendo que, nas relações internacionais, ainda é uma ferramenta a ser explorada e desenvolvida.

A Guiana passou por duas fases distintas de domínio da cena política por determinados grupos, cujos períodos de governo servem para organizar o presente texto. A primeira fase ocorreu desde a independência, em 1966, até 1992, tendo no governo o People's National Congress/Reform (PNC/R), partido que manteve as cadeiras de presidente e primeiro-ministro no período. A segunda fase ocorreu de 1992 a 2015, quando o domínio foi do People’s Progressive Party/Civic (PPP/ CIVIC). Além da introdução e da conclusão, o texto possui três partes, sendo a primeira referente à discussão sobre a path dependence, a segunda sobre o período do governo do PNC/R e a terceira abordando o governo do PPP/CIVIC.

\section{Path dependence: origem e elementos constitutivos}

O institucionalismo histórico é um ramo de estudos das ciências que associa as decisões tomadas pelos atores aos arranjos institucionais existentes, considerando ainda que existe uma relação causal social entre uma decisão tomada em um dado momento e seus efeitos futuros. De forma mais simplificada, pode-se dizer que a história importa e as instituições moldam as ações dos indivíduos. 
Além da causalidade histórica, a perspectiva histórico-institucional considera que cada passo na direção de uma determinada trajetória consolida o caminho escolhido e gera uma dependência de certos fatores presentes nesse percurso, ou seja, uma dependência da trajetória ou path dependence ${ }^{4}$.

A conceituação e o desenvolvimento da ideia de path dependence tiveram sua gênese na economia, a partir das críticas às premissas da economia neoclássica, tendo como precursores Brian Arthur, com a teoria dos retornos crescentes (increasing returns) (ARTHUR, 1994), e Paul David, que abordou o fenômeno como um irreversível processo de ramificação (branching) (DAVID, 1997). Na ciência política, Paul Pierson foi um dos responsáveis pela difusão do debate a partir da path dependence, considerando a ideia de increasing returns, bem como a importância do momento (timing) e da sequência de eventos (sequence) que levam a uma mudança institucional (PIERSON, 2000)5.

Ruth Berins Collier e David Collier trouxeram para tal debate uma questão que faz parte das abordagens de Arthur, David, Pierson e outros, aprofundando a discussão sobre a forma como conjunturas críticas (critical junctures) afetam um fenômeno path dependent (COLLIER; COLLIER, 2002). Aproximando-se de questões metodológicas, James Mahoney realizou uma explanação sobre a utilização das ferramentas metodológicas da path dependence para estudos sociológicos (MAHONEY, 2000). Andrew Bennett e Colin Elman trataram de questões metodológicas envolvendo a path dependence, demonstrando como o uso da comparação e do process tracing podem esclarecer casos de dependência da trajetória (BENNETT; ELMAN, 2006), além de destacar que os estudos qualitativos cada vez mais têm focado na busca de teorias que envolvam diferentes formas de compreensão, sendo que path dependence é uma das opções que podem levar à resolução das problemáticas de pesquisa (BENNETT; ELMAN, 2008).

Embora os estudos comparados e estudos históricos que abordam os efeitos de decisões passadas no desenvolvimento futuro tenham uma longa tradição na ciência política, a path dependence passou a ser mais utilizada, tanto na economia como na ciência política e em outros campos de estudo, a partir do trabalho de Brian Arthur (1994), por conta da sua definição de uma teoria das condições que

4 Optou-se por utilizar a denominação dos conceitos em inglês para manter os termos apresentados pelos autores utilizados e para evitar equívocos com o uso de palavras semelhantes à tradução em português no corpo do texto.

5 Para Pierson, alguns aspectos dos processos políticos que não estão presentes na economia e que devem ser considerados em análises de dependência da trajetória, tais como o papel da ação coletiva, a densidade das instituições, as assimetrias de poder e a complexidade intrínseca aos processos políticos (PIERSON, 2004). 
produzem a dependência da trajetória. No campo das relações internacionais, apesar de também ser possível encontrar uma produção científica com análises a partir da path dependence, trata-se de trabalhos com discussões recentes ${ }^{6} \mathrm{e}$ em pouca quantidade? . Uma questão que frequentemente surge, quando certas abordagens são pouco utilizadas em determinada área, é se tal carência poderia estar relacionada à insuficiência de tal abordagem para um dado objeto. No caso em questão, alguns trabalhos têm demonstrado o potencial da path dependence para o campo de estudo das relações internacionais.

No debate sobre a posição da path dependence nos estudos em relações internacionais, Andrew Hurrel e Terry Macdonald discutem como a moral, a ética e as ideias influenciam o comportamento político e como o comportamento moral é influenciado pela dinâmica das mudanças na política global. Situam a path dependence no campo da visão racionalista, destacando como as normas afetam os resultados de uma decisão política (HURRELL; MACDONALD, 2013). Duncan Snidal ressalta que, nas relações internacionais, a rational choice não é suficiente para realizar predições, enquanto que os estudos históricos são insuficientes para explicar as mudanças de status quo entre anarquia e cooperação. Para o autor, a path dependence, apesar de sofrer críticas e possuir limitações, pode dialogar com essas perspectivas e servir como ferramenta complementar (SNIDAL, 2013). John Ikenberry defende que o institucionalismo histórico apresenta ferramentas de análise - como a path dependence, os increasing returns e as critical junctures - que podem esclarecer fenômenos que as abordagens baseadas na análise de distribuição de poder no sistema internacional não são capazes de explicar, tais como mudanças na ordem mundial (IKENBERRY, 2016). Emmanuel Adler, um dos teóricos do construtivismo nas relações internacionais, em texto que debate a evolução dessa perspectiva na disciplina, afirma que o construtivismo não utiliza a história como um método descritivo, mas como parte da própria teoria. Para Adler, a historicidade na perspectiva construtivista emerge em processos de path dependence que envolvem a relação agente-estrutura e que explicam os mecanismos envolvidos em uma mudança de trajetória (ADLER, 2013). Em um estudo sobre as teorias do desenvolvimento nas relações internacionais,

6 O livro de Fioretos, Falleti e Sheingate (2016) possui 38 capítulos sobre institucionalismo histórico e uma seção com 8 artigos com temáticas exclusivas das RI, dos quais apenas dois utilizam a path dependence em suas análises.

7 O Handbook of International Relations (CARLSNAES; RISSE; SIMMONS, 2013) apresenta 33 capítulos, dos quais apenas quatro discutem em alguma medida a path dependence, sua importância e potencial como ferramenta analítica para as RI. No entanto, em nenhum deles essa perspectiva é utilizada como metodologia ou apoio teórico. 
Jana Hönke e Markus Lederer destacam a importância da path dependence na literatura neoinstitucionalista que debate a teorização do desenvolvimento, tal como na análise da distribuição de recursos por parte de determinados Estados, em benefício de suas colônias (HÖNKE; LEDERER, 2013).

Ainda que escassas, podem ser encontradas, na esfera das relações internacionais, abordagens que utilizam a path dependence como ferramenta metodológica, como etapa de análise através do institucionalismo histórico ou como base teórica para formulação de hipóteses. Etel Solingen e Wilfred Wan analisam as divergências entre os paths da segurança regional no Leste Asiático e no Oriente Médio, além do regime de não proliferação de armas nucleares, utilizando o institucionalismo histórico. Concluem que a path dependence é pertinente para entender um tratado que separa os Estados em duas classes, os nucleares e os não nucleares. Também demonstram que a path dependence pode revelar que as mesmas propriedades em um fenômeno não geram os mesmos resultados em diferentes situações (SOLINGEN; WAN, 2016). Mahoney, em estudo comparativo sobre a mudança de regime político nos países da América Central no final do século XIX e início do século XX, apoia-se na path dependence para formulação de suas hipóteses e definição de seus argumentos, bem como as variáveis de seu modelo analítico (MAHONEY, 2001). Stefan Hedlund realizou um estudo sobre a path dependence na economia política internacional da Rússia, utilizando os postulados de Brian Arthur, por sugestão de Paul David, analisando como a dependência da trajetória influenciou historicamente as relações da Rússia com outros países e regiões (HEDLUND, 2005). Embora a pesquisa realizada por Mahoney seja mais próxima da ciência política e a de Hedlund mais ligada à economia, ambos trazem importantes aportes do uso da path dependence que podem ser observados pela ótica das relações internacionais. Esses trabalhos exemplificam as possibilidades de uso da path dependence nas relações internacionais, bem como a necessidade do desenvolvimento de um arcabouço teórico-metodológico agregado a esta área da ciência.

\section{Path dependence como modelo de análise}

A path dependence, a partir da perspectiva do desenvolvimento histórico, tal como citado anteriormente, pode ser entendida como uma dependência gerada pela trajetória traçada em determinado caminho, escolhido em um dado momento histórico, dependência essa que se consolida a cada passo trilhado na mesma 
trajetória. Quanto a essa afirmação, não há divergências entre os estudiosos do tema, sejam da economia, da ciência política ou das relações internacionais. No entanto, é necessário um melhor entendimento dos mecanismos que envolvem a path dependence para a sua utilização como um modelo analítico. Nesse tópico do texto, são apresentados os conceitos utilizados na análise deste artigo: a) critical juncture; b) contingent event; c) antecedent conditions; d) self reinforcing.

Critical junctures são períodos nos quais há a seleção de uma opção dentre diversas alternativas (MAHONEY; SCHENSUL, 2006), gerando um movimento na direção selecionada e um processo causal relacionado à alternativa eleita (COLLIER; COLLIER, 2002). Mahoney desenvolve a ideia de que as critical junctures são momentos de escolha nos quais uma opção é adotada em detrimento das demais, tornando progressivamente mais difícil retornar ao ponto inicial no qual múltiplas alternativas estavam disponíveis, gerando uma trajetória que não pode ser facilmente interrompida ou revertida (MAHONEY, 2001). Complementa com a afirmativa de que, quando as condições que precedem uma critical juncture podem predizer ou explicar os resultados da decisão tomada, a sequência de eventos que se sucederem não podem ser considerados path dependents. Sendo assim, uma critical juncture é uma condição presente no início de uma trajetória dependente ou em momentos de tomada de decisão dentro dessa trajetória. Além disto, a definição de uma critical juncture auxilia no problema do estabelecimento do quanto se deve retornar ao passado para explicar um fenômeno, ou seja, serve como base para o recorte da pesquisa (MAHONEY, 2001).

Assim, como as critical junctures, um contingent event está ligado às condições iniciais de uma trajetória dependente. Entretanto, há grandes diferenças sobre o entendimento desse elemento na path dependence. Alguns autores consideramno como um fator aleatório e inexplicável com efeito causal nos momentos de critical junctures, enquanto que outros consideram que possa ser um elemento explicável, mas exógeno ao fenômeno em análise, além de necessário para que ocorra a path dependence. Outros autores consideram que o contingent event não é condição suficiente e nem necessária para a existência da path dependence (BERNARDI, 2012). Adota-se, neste trabalho, a premissa mais geral de que um contingent event é um acontecimento ligado à fase inicial de um processo path dependent e às critical junctures, mas considera-se também a posição de Kathleen Thelen de que as trajetórias políticas não são necessariamente desencadeadas por um evento inicial contingente, pois suas origens podem estar mais fortemente ligadas às antecedent conditions (THELEN, 1999). 
As antecedent conditions são características historicamente construídas, que definem a extensão das alternativas disponíveis aos decision makers, mas não determinam qual alternativa será escolhida (CAPOCCIA, 2015). Como parte das antecedent conditions, Capoccia aponta que atores estrategicamente dispostos nos momentos de critical junctures podem usar sua posição para difundir ideias que legitimam uma escolha em particular, prevalecendo sobre outros grupos sociais. Quando essa batalha de ideias encontra um vencedor, as ações coletivas passam a ocorrer no sentido da construção e do suporte ao caminho escolhido (CAPOCCIA, 2015). Mahoney e Schensul (2006), assim como Collier e Collier (2002), concordam com Capoccia na afirmativa de que as antecedent conditions são elementos necessariamente existentes antes das critical junctures e da ocorrência de crises ou cleavages. Assim, as antecedent conditions podem ser entendidas como as características de um fenômeno, que antecedem um momento de crise e levam a uma critical juncture, na qual ocorrerá a tomada de decisão.

As antecedent conditions, critical junctures e contingent events são elementos que caracterizam o processo inicial de uma condição path dependent. Todavia, para que se produza a dependência da trajetória é necessário que a opção selecionada seja reproduzida, tomando atitudes que reforcem a decisão anterior. Na economia, a abordagem mais comum para explicar a razão pela qual uma opção selecionada é reproduzida são os increasing returns ou feedbacks positivos, ligados a uma abordagem utilitarista e racional. No caso da política, que se aplica também às relações internacionais, é importante resgatar a afirmação de Pierson de que a retroalimentação de uma trajetória deve considerar a possibilidade de uso da posição de um determinado ator nas disputas de poder (PIERSON, 2004), frequentemente assimétricas. Devido a tais características, utiliza-se neste texto o termo self reinforcing para designar as ações voltadas a reproduzir uma opção. Entende-se que o termo increasing returns (ARTHUR, 1994) é mais útil em análises com base racionalista. Também não se utiliza a expressão positive feedback (PIERSON, 2000), empregada com frequência de maneira intercambiável com self reinforcing, pois entende-se que o positive feedback, assim como os increasing returns, são os fatores motivadores para uma ação de self reinforcing.

A partir da visão de que os mecanismos que definem a fase inicial de uma condição de path dependence são diferentes daqueles que reproduzem tal condição (COLLIER; COLLIER, 2002), é possível entender o self reinforcing como uma decisão ligada à opção inicial ou influenciada por ela, que necessariamente conduz a trajetória ao lock-in ou situação de irreversibilidade da trajetória. Nesse 
caso, o custo da transição para uma alternativa torna-se inviável, permitindo apenas a adoção de opções que gerem um processo de branching, que se trata de um padrão de mudanças que se restringem a ramificações dentro da mesma trajetória (DAVID, 1997). Essa limitação de escolhas que se acentua ao longo do horizonte histórico é um dos temas sobre os quais há uma quase unanimidade entre os estudiosos da path dependence, que consideram que as escolhas feitas na fase de formação de uma instituição ou da definição de uma política terão influência determinante e contínua ao longo do tempo. Em um processo path dependent em que ocorrem sequências de self reinforcing, as critical junctures são períodos de gênese institucional (MAHONEY, 2000) ou mesmo de mudanças dentro de um mesmo processo de path dependence (MAHONEY; MOHAMEDALI; NGUYEN, 2016). O self reinforcing é uma etapa posterior à critical juncture, que reproduz uma opção selecionada anteriormente, promovendo uma persistência do caminho, gerando o lock-in, e tornando a dinâmica mais path dependent a cada passo na trajetória.

A partir da explanação dos conceitos ligados à path dependence que são utilizados na presente análise, pode-se definir a path dependence, para o objetivo deste artigo, como uma situação iniciada em uma critical juncture, na qual ocorreu uma tomada de decisão influenciada por antecedent conditions e que permaneceu ativa por conta do mecanismo de self reinforcing, levando ao lock-in institucional. Entretanto, é importante acrescentar que uma trajetória dependente pode ser substituída em momentos de ruptura da trajetória (path broken) ou alterada pelo mecanismo de branching dentro dos padrões impostos pela escolha realizada na fase de critical juncture. As seções seguintes do texto abordam o estudo do caso da Guiana, considerando os elementos da path dependence.

\section{Europa e Caribe na Agenda: o Governo do PNC/R (1966-1992)}

A Guiana tornou-se independente da Inglaterra em 1966, sendo que, no período desde a independência até 1970, teve a rainha Elizabeth II da Inglaterra como chefe de Estado e o primeiro-ministro, Forbes Burnham, do PNC/R, como chefe de governo. O período, que se iniciou em 23 de fevereiro de 1970 na Guiana, marcou o início da sua história como um Estado republicano, a República Cooperativa da Guiana, desfazendo os laços institucionais de governo com a monarquia britânica. O primeiro presidente republicano foi Arthur Chung (1970-1980), que não era 
filiado a nenhum partido na ocasião de sua eleição, que ocorreu de forma indireta, através dos votos dos parlamentares da Assembleia Nacional.

Durante todo o governo Chung, Burnham continuou sendo o primeiro-ministro e era quem exercia o poder de fato, utilizando-se de sua liderança político-partidária e da sua condição constitucional de principal assistente do presidente nas questões do executivo, principalmente na função de líder do governo perante a Assembleia Nacional. Em 1980, Burnham foi eleito presidente da Guiana, governando entre 1980 e 1985, quando faleceu e foi substituído pelo primeiro-ministro Desmond Hoyte, também do PNC/R, que governou até 1992. No período em que o PNC/R dominou a cena política, principalmente nos primeiros anos da Guiana republicana, foram tomadas as primeiras decisões em relação à inserção internacional e à política externa guianense, inclusive nos temas relativos à incorporação a processos de integração e adesão a organizações internacionais, como o CARICOM, ou manutenção de relações anteriores à independência, tal como a Commonwealth.

\section{A commonwealth e o ACP Group of States}

A British Commonwealth, foi institucionalizada em 1931 pelo governo britânico através do Estatuto de Westminster, como consequência da Conferência Imperial da Commonwealth de 1926. A principal alteração que a Commonwealth trouxe às colônias britânicas foi a mudança de sua condição de territórios coloniais para domínios autônomos, iguais em status, nenhum deles sendo subordinado aos demais, unidos pela fidelidade à Coroa e livremente associados como membros da Commonwealth. O estatuto previa ainda a autonomia legislativa de cada unidade e o direito de deixar de fazer parte da instituição quando assim desejasse (UNITED KINGDOM, 1931).

Em 1932, foi incluída uma dimensão econômica com a criação da Commonwealth Preference, um sistema que eliminou as tarifas dos produtos que a Inglaterra comprava de seus domínios; nessa ocasião, a Coroa recomendou que os domínios passassem também a realizar tal prática entre si. Essas medidas fizeram com que a Commonwealth atuasse como um bloco econômico nos anos seguintes, com o comércio entre seus membros vindo a reduzir-se somente ao final dos anos 1960 (FEDERAL RESEARCH DIVISION, 1993). Outro ponto importante é que os domínios tinham como autoridade máxima o representante da Coroa, ou seja, o monarca britânico. Aos domínios que alcançaram a sua independência, ficava a prerrogativa de manter a monarquia na função de chefe de Estado ou desfazer 
tais laços, o que não implicava retirada da Commonwealth, somente a condição de fazer parte do Reino da Commonwealth, composto por monarquias parlamentaristas independentes que compartilham o chefe de Estado.

No caso da Guiana, após a independência o país manteve-se na categoria de Reino da Commonwealth até a posse do presidente Chung, em 1970, quando se instaurou o modelo republicano e, ainda assim, a Guiana optou por seguir participando da Commonwealth. Na visão de Joshua Hyles, uma das principais motivações para que a Guiana permanecesse na Commonwealth era manter a possibilidade de solicitação de auxílio aos britânicos no caso da disputa territorial que ocorria com a Venezuela, pois o apoio inglês seria um freio às pretensões do país vizinho, caso esse resolvesse utilizar a força para a resolução da questão fronteiriça (HYLES, 2013). George Fauriol concorda com Hyles e acrescenta que uma segunda motivação era seguir usufruindo dos benefícios comerciais providos pelas preferências tarifárias (FAURIOL, 1993). Nesse caso, há que se destacar que, após a Segunda Guerra Mundial, as trocas comerciais entre os membros da Commonwealth reduziram-se, com a situação se agravando quando a Inglaterra passou a compor a Comunidade Econômica Europeia (CEE), o que levou a Commonwealth Preference a ser gradualmente abolida, sendo extinta em 1977 (FEDERAL RESEARCH DIVISION, 1993).

A realidade que a Commonwealth construiu desde os anos 1930 entre a Inglaterra e suas colônias deu a tônica das antecedent conditions que o primeiro governo da Guiana independente encontrou no momento de decidir as diretrizes internacionais do país, influenciando para que o país se mantivesse mais inclinado à Europa em suas relações internacionais. A independência da Guiana pode ser entendida como uma critical juncture, pois foi o momento no qual os governantes tiveram a possibilidade de escolher uma alternativa entre várias disponíveis, visto que, além da Commonwealth, havia a possibilidade de alinhamento com uma das grandes potências da Guerra Fria, reduzindo os laços com o eixo europeu. Todavia, a Guiana optou por manter os laços com a Commonwealth e aderir ao Non Aligned Movement (NAM), adotando uma política interna de cunho socialista, mas com uma política externa de neutralidade em relação às grandes potências. Assim, a Commonwealth foi a opção de inserção internacional vista como mais viável, em detrimento do alinhamento às grandes potências. Destarte, a adesão ao NAM e a posição neutra na Guerra Fria não significaram inexistência de relações da Guiana com os Estados Unidos ou com a União Soviética, pois as relações diplomáticas e comerciais ocorreram com ambos. 
O que é relevante para uma análise com base na path dependence é que a Guiana iniciou sua trajetória independente em uma critical juncture, que foi a fase imediatamente posterior à independência. Nessa situação, a decisão pela manutenção das relações com a Commonwealth, como principal linha de inserção internacional, foi o resultado das antecedent conditions construídas pela própria Commonwealth e de um contingent event, que era o conflito fronteiriço com a Venezuela. Ambas as causas podem ser consideradas uma herança colonial, pois a forte ligação com a Commonwealth foi institucionalizada pela Inglaterra no período colonial, enquanto que o conflito fronteiriço também é um tema sem solução desde 1814, quando a Convenção de Londres passou a região para o comando britânico.

Após a fase de critical juncture do pós-independência e o aprofundamento das relações com a Commonwealth, a Guiana ficou sujeita às flutuações inerentes às situações de path dependence. Com o avanço do processo de institucionalização da integração na Europa e a adesão definitiva do Reino Unido à Comunidade Econômica Europeia (CEE), em 1973, o eixo estrutural econômico da Commonwealth alterou-se, levando a modificações nas preferências tarifárias dos países da comunidade com o Reino Unido, as Commonwealth Preferences. Em fevereiro de 1975 foi assinada a Convenção de Lomé, entre os Estados partes do tratado que estabeleceu a CEE e os países que passariam a compor o African, Caribbean and Pacific Group of States (ACP). Tal convenção tinha o objetivo de promover a cooperação comercial entre as partes contratantes, levando em conta o nível de desenvolvimento de cada um dos países e a necessidade de se assegurar benefícios adicionais aos países da ACP, para garantir o seu acesso aos produtos da CEE e acelerar suas taxas de crescimento (THE LOME CONVENTION, 1975). Para os países da Commonwealth, tal como a Guiana, esse tratado serviu como substituição às Commonwealth Preferences, que vinham sendo reduzidas desde 1973 e foram extintas em 1977. Quando a Convenção de Lomé foi assinada, a ACP não existia formalmente, o que ocorreu somente em junho de 1975, através do Tratado de Georgetown, que denominou o conjunto dos países signatários como ACP-Group of States (THE GEORGETOWN AGREEMENT, 1975).

A adesão à ACP representou um aprofundamento das relações com a Europa, pois o tratado foi assinado com o bloco de países e não mais com o Reino Unido. A realidade guianense, quando foram eliminadas as Commonwealth Preferences e assinada a Convenção de Lomé, era de um país dependente no contexto internacional, muito mais do que uma nação capaz de conduzir uma política 
externa independente, baseada em algum interesse nacional. Essas condições, assim como decisões anteriores da fase de critical juncture, colocaram a Guiana em uma situação de path dependence com o Reino Unido através da Commonwealth, enquanto que a ACP significou um self reinforcing a tal trajetória, por conta da reprodução da opção escolhida anteriormente.

A persistência estrutural da trajetória selecionada foi ainda reforçada quando foi promulgada a Constituição da República Cooperativa da Guiana, de 1980, que caracterizou outro self reinforcing. A constituição guianense quebrou definitivamente todas as ligações com a monarquia britânica, mas reafirmou sua participação na Commonwealth, citando a instituição em onze dos seus 233 artigos (GUYANA, 1980). Dentre os temas tratados na constituição, o principal é o reconhecimento de cidadania e direitos a cidadãos de outros Estados da Commonwealth residentes na Guiana, com os mesmos direitos de cidadãos guianenses.

A relação com a Commonwealth e com a ACP evidenciam a manutenção de uma trajetória, exatamente nas primeiras décadas após a independência, período em que a Guiana poderia iniciar a superação dos antigos vínculos coloniais. No entanto, as antecedent conditions foram essenciais para determinar a trajetória vinculada aos antigos parceiros europeus e por eles determinada, em detrimento da exploração dos atributos materiais do Estado ou capabilities, tais como poder militar, posse de recursos naturais, características da sociedade e poder econômico.

\section{A agenda regional: CARICOM}

Além da inserção internacional via Europa, o governo guianense, nos anos de 1970, passou também a investir esforços na integração com o Caribe, a partir de 1973, quando o país passou a fazer parte do Caribbean Community and Commom Market (CARICOM). O CARICOM foi institucionalizado em 1973 com a assinatura do Tratado de Chaguaranas por Barbados, Guiana, Jamaica e Trinidad e Tobago, em substituição ao Caribbean Free Trade Agreement (CARIFTA). O CARIFTA era um tratado de livre-comércio criado em 1965, com o intuito de unir as economias dos antigos domínios britânicos no Caribe, que haviam se tornado independentes naquele período, com o objetivo de aumentar sua capacidade de barganha no cenário internacional. Hyles aponta que o CARIFTA não era um processo com a intenção de realizar uma integração pan-caribenha, mas um acordo comercial com o intuito de reagir à mudança do foco da política externa britânica, que se voltava naquele momento totalmente para a Europa (HYLES, 2013). 
Com o avanço da integração europeia e com a participação britânica no processo, também no Caribe os países passaram a tratar a integração de outra forma. O CARIFTA deixou de existir, sendo substituído pelo CARICOM, que possuía objetivos que estavam além do livre-comércio. Melhoria das condições de trabalho e emprego, avanço no desenvolvimento social e cultural, além da intensificação da cooperação em áreas como saúde e educação, eram temas da agenda da instituição. A Guiana teve importante papel em ambos os casos, propondo a ideia do CARIFTA e posteriormente sediando o escritório central do CARICOM. Assim, pode-se perceber que a face caribenha da inserção internacional da Guiana através de processos de integração e de participação em organizações internacionais teve sua gênese na mesma critical juncture em que houve o direcionamento das relações para a Europa, ou seja, a fase da independência. O que se altera é o contingent event, que nesse caso foi a participação britânica no processo de integração europeia. Apesar da ligação entre Europa e Caribe pela ACP, os Estados caribenhos, muitos deles recentemente independentes como a Guiana, perceberam a necessidade de aprofundar as relações regionais geograficamente mais próximas. A Guiana foi protagonista nesses processos, sendo propositora do CARIFTA, que se caracterizou por ser a alternativa selecionada na critical juncture, além de ter a sede do CARICOM, que significou um self reinforcing da inserção internacional regional guianense.

Contudo, nos doze anos (1973-1985) em que o CARICOM esteve em atividade e que Burnham exerceu o cargo de primeiro-ministro e, posteriormente, de presidente da Guiana, as relações com os demais países dentro da instituição foram problemáticas. Dos treze países da comunidade, somente a Jamaica, Granada e a Guiana tinham uma retórica anti-EUA, enquanto que os demais Estados eram marcados por uma política de apoio ao Ocidente e ao capitalismo, o que estava gerando desentendimentos no âmbito decisório do CARICOM, devido ao posicionamento crítico de Burnham em relação aos EUA. Deve-se destacar que o discurso de Burnham não era somente anti-EUA, mas também de críticas à União Soviética, afirmando que o país não serviria de peão nem ao Leste e nem ao Oeste (JACKSON, 2003), mas sem romper os laços com nenhuma dessas nações. A situação agravou-se com a intervenção dos EUA em Granada, em 1983, quando Burnham criticou tanto a ação norte-americana quanto os líderes do CARICOM e da Commonwealth que apoiaram a operação. Com isto, Burnham afastou-se dos demais líderes da Commonwealth, chegando a ameaçar o futuro do CARICOM (FAURIOL, 1993). Tal situação somente foi alterada quando Hoyte substituiu Burnham na presidência. 
Após a morte de Burnham, em 1985, Desmond Hoyte assumiu o governo até 1992. No período de Burnham no governo, não obstante o fato de manter o não alinhamento nas questões políticas, a Guiana tinha laços diplomáticos com os governos comunistas do Leste Europeu, com a União Soviética e com Cuba. Quando Hoyte assumiu o poder, apesar de pertencer aos quadros do PNC/R, adotou uma política externa menos tolerante com as causas socialistas, encerrando a retórica anticapitalista e antiocidental, inaugurando uma nova estratégia para obter apoio das potências ocidentais para a implementação de sua política econômica. As relações com o CARICOM e com os líderes dos países da Commonwealth foram reassentadas, ao passo que, com as nações comunistas, o relacionamento foi não mais que de cordialidade, levando ao arrefecimento ao longo dos anos seguintes (FAURIOL, 1993).

No âmbito da relação com as organizações internacionais, o ponto mais relevante do governo Hoyte foi a adesão à Organização dos Estados Americanos, em 1991. A despeito da adesão somente nesse período, a Guiana pleiteava a participação na organização desde a sua independência, em 1966, mas tinha essa possibilidade vetada pela Venezuela, por conta de um litígio fronteiriço entre os dois países. Apesar da tentativa do Reino Unido de mediar as negociações para a resolução da questão, ainda em 1966, não foi possível realizar um acordo e o conflito se estendeu até 1989, quando o presidente venezuelano era Jaime Lusinchi. Quando Carlos Andrés Pérez assumiu o governo, em substituição a Lusinchi, as negociações se tornaram menos conflituosas e mais cordiais, levando a Venezuela a retirar sua objeção à entrada da Guiana na OEA. Com isso, a partir de 1990, a Guiana passou a fazer parte também da organização, embora o tema fizesse parte da agenda e das diretrizes políticas desde 1966, ano em que a Guiana também aderiu à Organização das Nações Unidas.

\section{Continuidades e novas opções: o Governo do PPP/CIVIC (1992-2015)}

Durante o governo do PPP/CIVIC, ocorreu uma transformação políticoeconômica na qual o grupo governista absteve-se das políticas dos governos anteriores, direcionando sua matriz de inserção internacional a uma abertura econômica e à prática de políticas de livre mercado (FAURIOL, 1993). Em relação à política externa da Guiana e sua relação com as organizações internacionais e processos de integração nesse período, destaca-se a participação em cinco 
instituições: Association of Caribbean States (ACS), União de Nações Sul-Americanas (UNASUL), Comunidad de Estados Latinoamericanos y Caribeños (CELAC) e o Mercado Comum do Sul (MERCOSUL), além do Acordo de Cotonou, no âmbito da ACP. A adesão a tais instituições demonstra tanto ações que representam uma continuidade quanto parcerias que implicam uma mudança na política externa guianense. Ao mesmo tempo, são consequências mais ligadas aos condicionantes externos e ao contexto internacional do que necessariamente uma mudança de planejamento das diretrizes externas do país, visto que as alterações no direcionamento de sua política externa foram influenciadas, em grande medida, pelo avanço da integração europeia e pela consolidação de instituições sul-americanas.

\section{Self reinforcing: ACS e Cotonou}

A Guiana passou a compor a Association of Caribbean States (ACS) desde a sua fundação, em 1994. A ACS constitui-se de conferências de cúpula realizadas por chefes de Estado ou representantes de alto nível, com fins de promoção de cooperação regional e integração econômica entre os países caribenhos, com o objetivo de promover a cooperação e ação concentrada dos Estados membros (ASSOCIATION OF CARIBBEAN STATES, 2012). Para tanto, a ACS identificou áreas de interesse comum aos países membros, como a preservação e conservação do mar do Caribe, o turismo sustentável, o comércio e as relações econômicas internacionais, os desastres naturais e as questões de transporte e infraestrutura.

Ao analisarem-se as áreas de interesse dos países membros, nota-se uma semelhança com diversos temas também tratados pelo CARICOM. No entanto, conforme destaca a própria ACS, enquanto que o CARICOM possui quinze membros, a ACS possui 25 Estados membros independentes, além de oito países associados. Outra diferença entre os dois é que o CARICOM tem seu foco principal em um mercado comum e outras questões econômicas, com o objetivo de gerar um processo de integração. A ACS, por sua vez, é um foro consultivo e deliberativo, que tem o intuito de gerar uma zona de cooperação nas diversas áreas de interesse identificadas (ASSOCIATION OF CARIBBEAN STATES, 2012). Assim, tanto a ACS quanto o CARICOM são instituições das quais a Guiana participa e que estão geograficamente voltadas às questões caribenhas.

Desde a fundação do CARIFTA até a institucionalização da ACS, pode-se considerar que a integração da Guiana voltada para o Caribe completou três 
décadas de desenvolvimento, consolidando um lock-in nessa questão. Os modelos de integração do CARIFTA, do CARICOM e da ACS demonstram uma evolução nos objetivos e na abrangência, sempre com foco no Caribe, reproduzindo a opção guianense dos anos 1960 em um processo de self reinforcing. O caminho traçado pela inserção internacional da Guiana, através da aproximação com países do Caribe, a cada novo evento apresentou decisões alinhadas com o lock-in existente, não contrastando, mas, sim, reforçando a opção inicial.

O mesmo pode-se apontar em relação à opção pela parceria com a Europa pela Commonwealth, que passou por outro self reinforcing no governo do PPP/ CIVIC. No ano de 2000, foi estabelecido um acordo entre o ACP-Group of States e a União Europeia, o ACP-UE, que consiste no estabelecimento de um processo de cooperação. Conhecido como Acordo de Cotonou, esse tratado entrou em vigor em 2003 e é uma continuação e atualização da Convenção de Lomé, representando uma nova fase de cooperação entre ambas organizações. O Acordo de Cotonou alterou as convenções anteriores, promovendo acordos comerciais e de cooperação entre as nações, tendo como objetivos a redução da pobreza e, a longo prazo, a sua erradicação e a integração progressiva dos Estados da África, do Caribe e do Pacífico (ACP) na economia mundial (EUROPEAN COMISSION, 2000). Mesmo antes da convenção entrar em vigência, no ano de 2002, a Guiana iniciou as negociações de Acordos de Parceria Econômica, com uma maior abertura do mercado para serviços e investimentos no âmbito do tratado.

Tanto no eixo europeu como no eixo caribenho da inserção da Guiana, considerando os momentos históricos em que cada um desses processos foi institucionalizado, é possível identificar a interferência de fatores sistêmicos influenciando na criação de tais instituições. Além disso, a condição dependente e periférica da Guiana também impõe limites nas possibilidades de escolha, fato que é característico de qualquer Estado periférico. A path dependence que teve sua gênese na critical juncture da independência, iniciando dois caminhos distintos e complementares para a política externa da Guiana, teve diversos eventos novos ao longo do tempo, cujas decisões estiveram em consonância com o lock-in e geraram self reinforcing. Para ambas as situações, os elementos sistêmicos próprios das relações internacionais geraram contingent events e as características da Guiana, dentro desse sistema internacional, estão ligadas às antecedent conditions de um país que ainda molda sua política independente. Durante o governo do PPP/CIVIC, apesar das divergências ideológicas com o PNC/R, a ACS e o Acordo 
de Cotonou representaram a continuidade e o reforço da trajetória iniciada, no período anterior, pelos governos de Chung, Burnham e Hoyte.

\section{Regionalismo sul-americano: UNASUL, CELAC e MERCOSUL}

Em outra direção, a Guiana participa da União de Nações Sul-Americanas (UNASUL), desde quando a instituição utilizava a antiga sigla CASA, em 2004. Criada em 2008, como etapa posterior da CASA, a UNASUL é uma organização que, desde a sua gênese, visa a criação de um espaço de integração dos povos sul-americanos, uma vez que, no período de seu surgimento, a região passava por profundas transformações políticas, econômicas e sociais. Não obstante, a criação da UNASUL resultou de um processo que buscava o fortalecimento dos países sul-americanos enquanto grupo, servindo inclusive como espaço de discussão e estabilização de conflitos regionais e de integração de infraestrutura física. A organização conta com uma presidência rotativa ${ }^{8}$ e, no período de 26 de novembro de 2010 a 29 de outubro de 2011, o então presidente da Guiana, Bharrat Jagdeo, assumiu tal função.

Para a Guiana, a UNASUL pode representar a oportunidade de resolver a questão relativa à disputa fronteiriça com a Venezuela, visto que o presidente venezuelano, no início de 2015, apontou para a possibilidade de levar a questão para discussão no órgão. Além disso, as eleições presidenciais na Guiana, em 2015, contaram com a participação de uma delegação de observadores da UNASUL (UNASUR, 2016), por solicitação do governo guianense, como forma de demonstrar o compromisso do país com a instituição e com um de seus objetivos, o de promover e preservar a democracia na América do Sul. A UNASUL se caracteriza, portanto, como uma forma de direcionamento da integração ao Sul para a Guiana, dentro das diretrizes de política externa do país.

Verifica-se que, a partir dos anos de 1990 até o início do século XXI, a inserção internacional guianense pela via da integração ocorreu através do estabelecimento de parcerias que aprofundaram os modelos existentes ou os aperfeiçoaram em um mecanismo de self reinforcing. Essa é a constatação quando se averiguam as semelhanças e diferenças entre o CARICOM e a ACS ou entre a Convenção de Lomé e o Tratado de Cotonou, que representaram uma atualização dos processos

8 A lista dos presidentes pro tempore da UNASUL está disponível no site da instituição: < https://goo.gl/R60DlV > . Acesso em: 22 de dezembro de 2017. 
herdados dos anos de 1970, que, por sua vez, têm raízes ainda mais longínquas, nas antecedent conditions. Todos esses exemplos, cada um com suas especificidades, derivam da participação da Guiana na Commonwealth desde o período colonial. A UNASUL, por sua vez, representou um ponto de inflexão, pois foi o primeiro processo de integração ao qual a Guiana aderiu que não tem como foco principal o Caribe e cuja matriz encontra-se na América Latina.

Esse é um fato relevante, pois, após esse período, o país inseriu-se em outros processos integracionistas latino-americanos, a partir do início da segunda década do século XXI, em decisões que contrastaram com o lock-in da inserção internacional voltada para a Europa e o Caribe. No entanto, não se pode caracterizar a adesão da Guiana à CASA, em 2004, e à UNASUL, em 2008, como um path broken ou uma nova critical juncture nas diretrizes de inserção internacional do país em processos de integração ou participação em instituições internacionais, pois, para tal, seria necessária uma alteração na trajetória, substituindo-a por uma alternativa concorrente. No caso em questão, a opção pela UNASUL deveria substituir ao menos uma das opções anteriores, as relações com o Caribe ou com as instituições europeias, o que não ocorreu. Sendo assim, a path dependence, em relação à Europa e ao Caribe, e o lock-in, institucionalizado ao longo das primeiras quatro décadas da Guiana independente, não foram alterados por conta do eixo latino-americano da inserção internacional guianense que se abriu no início do século XXI.

Em relação ao novo eixo da inserção guianense, uma importante relação estabelecida pelo governo do PPP/CIVIC foi com a Comunidade dos Estados Latino-americanos e Caribenhos (CELAC). A Guiana aderiu à CELAC desde a sua fundação, em 2011, a partir de quando ocorreu uma união progressiva do Grupo do Rio e da Cúpula da América Latina e do Caribe sobre Integração e Desenvolvimento (CALC) em uma única organização. As cúpulas realizadas pela CELAC tornaram-se espaços de diálogo do continente com o resto do mundo, na medida em que têm propiciado o desenvolvimento e a coordenação de relações inter-regionais.

Por ocasião da cúpula ministerial realizada na Costa Rica, em 2015, o ministro de Negócios Estrangeiros da Guiana, Carl Greenidge, declarou que a CELAC permite às nações latino-americanas falarem no contexto de um grupo maior, o que pode ser, para países maiores, uma perspectiva mais atraente do que lidar com países pequenos isoladamente (GOVERNMENT INFORMATION AGENCY, 2016). Ademais, 
Greenidge reforçou tal posição, afirmando que a CELAC deveria buscar relações com a União Europeia e com a União Africana, considerando o posicionamento da América Latina no mundo.

Tanto a CELAC quanto a UNASUL fazem parte de iniciativas surgidas em um momento histórico em que ocorreu um realinhamento em âmbito internacional. A América Latina da primeira década do século XXI estava caracterizada por governos que buscavam alternativas aos modelos integracionistas baseados no regionalismo aberto e em políticas neoliberais, abrindo espaço para novas iniciativas regionais. Nesse contexto, o fortalecimento das relações latino-americanas fez emergir organismos como a UNASUL e a CELAC, que representaram, ao menos parcialmente, a aproximação de Estados que não tinham as suas prioridades em organismos regionais latino-americanos.

Além da UNASUL e da CELAC, também o MERCOSUL representa o direcionamento da política externa guianense para uma maior integração com a América do Sul. O MERCOSUL, criado em 1991, tem como membros efetivos Argentina, Brasil, Uruguai, Venezuela e Paraguai e, como associados, Chile, Peru, Colômbia, Equador e Bolívia, sendo que esse último se encontra em fase de adesão como membro pleno. No ano de 2013, o Suriname e a Guiana tornaram-se Estados associados e, assim, todos os Estados da América do Sul passaram a compor o bloco, como membros plenos ou associados (MERCOSUR, 2013).

A relação entre a Guiana e o MERCOSUL estabelece um marco para os processos de interesse na integração regional. Esse processo é estabelecido pelo Acordo Quadro de Associação entre o MERCOSUL e a República Cooperativa da Guiana, onde as partes consideram a integração regional um instrumento de desenvolvimento social e econômico, de modo que a experiência da integração regional da Guiana no Caribe torna-se benéfica a uma maior aproximação entre o MERCOSUL e o CARICOM. Para tal fim, o acordo de associação entre as partes acorda que o alcance dos objetivos estabelecidos se dará através do diálogo político, da cooperação e de investimentos (MERCOSUR, 2013). Todavia, a adesão da Guiana ao MERCOSUL ainda demanda ações conjunturais com o bloco, uma vez que, com os Estados do MERCOSUL, a Guiana tem promovido apenas relações bilaterais com o Brasil, através de processo de cooperação de tecnologia, formação de recursos humanos, segurança e defesa e de políticas sociais.

A participação da Guiana, desde a gênese da UNASUL, ainda quando se denominava CASA, pode não indicar uma critical juncture na perspectiva de um momento de seleção de uma alternativa em detrimento das demais (MAHONEY; 
SCHENSUL, 2006), mas, se for considerado o contexto, identifica-se um contingent event. O direcionamento das políticas externas de países como o Brasil, a Argentina e a Venezuela, para o fortalecimento do regionalismo latino-americano, levou os demais Estados da região a considerarem essa como uma opção a ser explorada. Com a Guiana não foi diferente e, ao aderir a tais processos, institucionalizou como uma de suas diretrizes de política externa a inserção internacional pelo eixo latino-americano. Se for considerada a perspectiva de que uma critical juncture é um período de gênese institucional (MAHONEY, 2000), pode-se afirmar que a participação na CASA foi a produção de um novo pathway, que passou por três eventos de self reinforcing, quando o país se manteve ativo na UNASUL, posteriormente aderiu à CELAC e, finalmente, ao MERCOSUL.

Como tratado anteriormente, no momento imediatamente seguinte à sua independência, a Guiana manteve as relações com antigos parceiros - Europa e Commonwealth - por conta das antecedents conditions. No caso da aproximação da Guiana em relação aos processos regionais de integração, houve grande influência do timing e das forças políticas que se mobilizavam para que avançasse a integração latino-americana, principalmente por parte do Brasil, da Venezuela e da Argentina. Em ambos os casos, seja pelas condições historicamente construídas ou pelo contexto regional, os condicionantes externos foram fatores preponderantes nas decisões tomadas pelo governo guianense. É inequívoco afirmar que os fatores externos sempre influenciam, em maior ou menor medida, o direcionamento da política externa de qualquer Estado, mas, no caso em questão, os dois momentos em que se verifica as tomadas de decisão mais importantes tiveram influência decisiva do contexto externo.

\section{Conclusões}

A partir da verificação dos processos de integração e das organizações internacionais que a Guiana passou a fazer parte em seu meio século como Estado independente, verificou-se que, nessas cinco décadas, o país passou por pelo menos três caminhos que estão moldando a sua trajetória de inserção internacional.

O primeiro deles está relacionado com os resquícios de um país que foi um dos últimos na América Latina a deixar de ser uma colônia. Trata-se das relações com o Reino Unido, que tornaram a Commonwealth uma das opções de parcerias internacionais da Guiana independente. Posteriormente, os Acordos 
de Lomé e Cotonou somente reforçaram tal trajetória. O segundo foi a organização de instituições voltadas à integração do Caribe, como o CARICOM, e mais tarde a ACS, organizações das quais a Guiana também passou a fazer parte com papel protagonista. Esses dois caminhos foram iniciados imediatamente após a independência e foram reforçados ao longo do tempo. O terceiro é a participação em processos voltados para a América Latina - UNASUL, CELAC e MERCOSUL que são mais recentes, mas marcam um novo espaço para a inserção internacional guianense.

Sobre a path dependence, pode-se verificar que, no eixo das relações com a Europa, a participação na Commonwealth foi influenciada pelas antecedent conditions da herança colonial, sendo um dos caminhos selecionados na critical juncture da independência, sofrendo processo de self reinforcing com as convenções de Lomé e Cotonou e com a Constituição de 1980. Nas relações caribenhas, a participação do Reino Unido na integração europeia serviu como contingente event, que gerou o CARIFTA. Posteriormente, o CARICOM e a ACS serviram como self reinforcing a tal processo. O eixo mais recente da integração latino-americana, por sua vez, não significou um path broken, visto que as opções anteriores não foram abandonadas, mas pode ser interpretado como uma critical juncture, devido à gênese institucional ocorrida, ou como um branching, se for considerado que a inserção internacional pela via da integração é uma instituição consolidada na Guiana independente.

Ao se adotar uma opção analítica para pesquisar sobre a ocorrência de determinado fenômeno, mesmo em trabalhos qualitativos, quase que invariavelmente é necessário que se deixem as premissas de outras perspectivas em segundo plano. Ao se analisar o caso da Guiana a partir de um dos enfoques do institucionalismo histórico, a path dependence, outras indagações despontam dentro do objeto em análise. Uma delas é a questão do grau de interdependência ao qual a Guiana tem se submetido ao longo desse meio século, o que permite questionar até que ponto a dependência desenvolvida na trajetória encontra - ou não - uma recíproca em sua outra extremidade, ou seja, nos países dos quais a Guiana depende. Outro ponto seria o papel das capabilities. A análise realizada não partiu da premissa de que as capabilities são um fator de importância secundária na tomada de decisão de um Estado, mas, no caso da Guiana, tais elementos ainda não têm sido explorados em todo o seu potencial, por conta da própria condição dependente e periférica do país. 


\section{Referências}

ADLER, E. Constructivism in International Relations: Sources, Contributions, and Debates. In: CARLSNAES, W.; RISSE, T.; SIMMONS, B. A. Handbook of International Relations. Londres: SAGE, 2013. Cap. 5, p. 112-144.

ARTHUR, W. B. Incresing returns and path dependence in the economy. Ann Arbor: The University of Michigan Press, 1994.

ASSOCIATION OF CARIBBEAN STATES. About The ACS. Association of Caribbean States, 2012. Disponível em: < http://www.acs-aec.org/index.php?q=about/faq > . Acesso em: 15 abr. 2016.

BENNETT, A.; ELMAN, C. Complex Causal Relations and Case Study Methods: The Example of Path Dependence. Political Analysis, n. 14, 2006. 250-267. Disponível em: < https://goo.gl/UCPylO > . Acesso em: 17 jun 2012.

BENNETT, A.; ELMAN, C. Historical Methods. In: REUS-SMIT, C.; SNIDAL, D. The Oxford Handbook Of International Relations. Oxford: Oxford University Press, 2008. Cap. 30, p. 518-538.

BERNARDI, B. B. O Conceito de Dependência da Trajetória (Path Dependence): Definições e Controvérsias Teóricas. Perspectivas, São Paulo, 41, 2012, p. 137-167.

CAPOCCIA, G. Critical junctures and institutional change. In: MAHONEY, J.; THELEN, K. Advances in Comparative-Historical Analysis. Cambridge: Cambridge University Press, 2015.

CARLSNAES, W.; RISSE, T.; SIMMONS, B. A. Handbook of International Relations. Londres: SAGE, 2013.

COLliER, R. B.; COLLIER, D. Shaping the Political Arena: Critical Junctures, the Labor Movement and Regime Dynamics In Latin America. Notre Dame: University Of Notre Dame Press, 2002.

DAVID, P. A. Path Dependence and the quest for historical economics: one more chorus of the ballad of QWERTY. Discussion Papers in Economic and Social History, 1997. EUROPEAN COMISSION. The Cotonou Agreement. Bruxelas: União Europeia, 2000. Disponível em: < https://ec.europa.eu/europeaid/where/acp/overview/cotonouagreement_en > . Acesso em: 11 abr. 2016.

FAURIOL, G. A. Guyana: Government and Politics. In: DIVISION, F. R. Guyana and Belize: country studies. Washington, D.C.: Library of Congress, 1993, Cap. 4, p. 107-130.

FEDERAL RESEARCH DIVISION. Guyana and Belize: country studies. Washington, D.C.: Library of Congress, 1993.

FIORETOS, O.; FAlleti, T. G.; SHEINGATE, A. The Oxford Handbook of Historical Institutionalism. Oxford: Oxford University Press, 2016. 
GOVERNMENT INFORMATION AGENCY. Greenidge to represent Guyana at CELAC Meeting, 2016. Disponível em: < http://www.gina.gov.gy/home/index.php/news/ news-by-ministries/ministry-of-foreign-affairs/item/5229-greenidge-to-representguyana-at-celac-meeting-guyana-attends > . Acesso em: 14 abr. 2016.

GUYANA. Constitution of the Co-operative Republic of Guyana. Georgetown: 1970.

GUYANA. Constitution of the Co-operative Republic of Guyana. Georgetown: 1980.

HEDLUND, S. Russian Path Dependence. Abingdon: Routledge, 2005.

HÖNKE, J.; LEDERER, M. Development and International Relations. In: CARLSNAES,

W.; RISSE, T.; SIMMONS, B. A. Handbook of International Relations. Londres: SAGE, 2013. Cap. 31, p. 775-800.

HURRELL, A.; MACDONALD, T. Ethics and Norms in International Relations. In: CARLSNAES, W.; RISSE, T.; SIMMONS, B. A. Handbook of International Relations. Londres: SAGE, 2013. Cap. 3, p. 57-84.

HYLES, J. R. Guiana and the Shadows of Empire: Colonial and Cultural Negotiations at the Edge of the World. Lanham: Lexington Books, 2013.

IKENBERRY, G. J. The Rise, Character, and Evolution of International Order. In: FIORETOS, O.; FALLETI, T. G.; SHEINGATE, A. The Oxford Handbook of Historical Institutionalism. Oxford: Oxford University Press, 2016. Cap. 32, p. 658-675.

JACKSON, R. Non-alignment and Guyana. Sunday Stabroek, Georgetown, 23 fev 2003. 12A-13A.

LIMA, E. C. L. Política externa do vizinho distante: Estudo de caso da República Cooperativa da Guiana. Tese de Doutorado. 172 f. Universidade de Brasília (UnB) / Universidade Federal de Roraima (UFRR) / Faculdade Latino-Americana de Ciências Sociais (FLACSO-Brasil), 2011.

MAHONEY, J. Path Dependence in Historical Sociology. Theory and Society, 29, n. 4, agosto 2000. 507-548. Disponível em: < http://www.jstor.org/stable/3108585 > . Acesso em: 17 jun 2012.

MAHONEY, J. The Legacies of Liberalism Path Dependence and Political Regimes in Central America. Baltimore: The Johns Hopkins University Press, 2001.

MAHONEY, J.; MOHAMEDALI, K.; NGUYEN, C. Causality and Time in Historical Institutionalism. In: FIORETOS, O.; FALLETI, T. G.; SHEIN, A. The Oxford Handbook of Historical Institutionalism. Oxford: Oxford University Press, 2016. Cap. 4, p. 71-89.

MAHONEY, J.; SCHENSUL, D. Historical Context and Path Dependence. In: GOODIN, R. E.; TILLY, C. Oxford Handbook of Contextual Political Analysis. Oxford: Oxford University Press, 2006. Cap. 24, p. 454-471.

MERCOSUR. Acordo-Quadro de Associação entre o MERCOSUL e a República Cooperativa da Guiana, 11 Julho 2013. Disponível em: < http://www.mercosur.int/innovaportal/ file/5564/1/2013_acordo_mercosul-guaiana_pt.pdf > . Acesso em: 14 abr. 2016. 
PIERSON, P. Increasing returns, path dependence and the study of politics. American Political Science Review, v. 94, n. 2, p. 251-267, 2000.

PIERSON, P. Politics in time: history, institutions, and social analysis. Princeton: Princeton University Press, 2004.

SNIDAL, D. Rational Choice and International Relations. In: CARLSNAES, W.; RISSE, T.; SIMMONS, B. A. Handbook of International Relations. Londres: SAGE, 2013. Cap. 4, p. $85-111$.

SOLINGEN, E.; WAN, W. Critical Junctures, Developmental Pathways, and Incremental Change in Security Institutions. In: FIORETOS, O.; FALLETI, T. G.; SHEINGATE, A. The Oxford Handbook of Historical Institutionalism. Oxford: Oxford University Press, 2016. Cap. 33, p. 676-698.

THE GEORGETOWN AGREEMENT. The Georgetown Agreement (formally establishing the African, Caribbean and Pacific Group of States, the "ACP Group”. Georgetown: ACP Secretariat, 1975. Disponível em: < http://www.wipo.int/wipolex/en/treaties/ text.jsp?file_id $=201070>$. Acesso em: 12 fev. 2016 .

THE LOME CONVENTION. The Lomé Convention. Bruxelas: Comissão Europeia, 1975. Disponível em: < http://www.eurostudium.uniroma1.it/documenti/cooperazione/ Lome_convention.pdf $>$. Acesso em: 12 fev. 2016.

THELEN, K. Historical Institutionalism in Comparative Politics. Annual Review of Political Science, 2, 1999. 369-404.

UNASUR. Memoria Anual 2014-2015. Quito: Union de Naciones Suramericanas, 2016.

UNITED KINGDOM. Statute of Westminster. Londres: Her Majesty's Stationery Office and Queen's Printer of Acts of Parliament, 1931. Disponível em: < http://www.legislation. gov.uk/ukpga/1931/4/pdfs/ukpga_19310004_en.pdf > . Acesso em: 14 jan. 2016. 